\title{
Model for the techno-economic analysis of common work of wind power and CCGT power plant to offer constant level of power in the electricity market
}

\author{
Z. Tomsic", I. Rajsl, M. Filipovic \\ e-mail:zeljko.tomsic@fer.hr; ivan.rajsl@fer.hr, matea.filipovic@fer.hr \\ Faculty of Electrical Engineering and Computing, University of Zagreb, Croatia
}

\begin{abstract}
Wind power varies over time, mainly under the influence of meteorological fluctuations. The variations occur on all time scales. Understanding these variations and their predictability is of key importance for the integration and optimal utilization of wind in the power system. There are two major attributes of variable generation that notably impact the participation on power exchanges: Variability (the output of variable generation changes and resulting in fluctuations in the plant output on all time scales) and Uncertainty (the magnitude and timing of variable generation output is less predictable, wind power output has low levels of predictability). Because of these variability and uncertainty wind plants cannot participate to electricity market, especially to power exchanges. For this purpose, the paper presents techno-economic analysis of work of wind plants together with combined cycle gas turbine ( CCGT) plant as support for offering continues power to electricity market. A model of wind farms and CCGT plant was developed in program PLEXOS based on real hourly input data and all characteristics of CCGT with especial analysis of techno-economic characteristics of different types of starts and stops of the plant.
\end{abstract}

The Model analyzes the followings: costs of different start-stop characteristics (hot, warm, cold start-ups and shutdowns) and part load performance of CCGT. Besides the costs, the technical restrictions were considered such as start-up time depending on outage duration, minimum operation time, and minimum load or peaking capability.

For calculation purposes, the following parameters are necessary to know in order to be able to economically evaluate changes in the start-up process: ramp up and down rate, time of start time reduction, fuel mass flow during start, electricity production during start, variable cost of start-up process, cost and charges for life time consumption for each start and start type, remuneration during start up time regarding expected or unexpected starts, the cost and revenues for balancing energy (important when participating in electricity market), and the cost or revenues for $\mathrm{CO}_{2}$ certificates. Main motivation for this analysis is to investigate possibilities to participate on power exchanges by offering continues guarantied power from wind plants by backing-up them with CCGT power plant.

\section{KEYWORDS}

Wind plant, CCGT plant, electricity market, PLEXOS model

${ }^{*}$ Corresponding author 


\section{INTRODUCTION}

Today energy market is very uncertain and represents a great challenge for new investments. In each moment in time production and consumption need to be in balance and load is covered by the production from various power sources. But different energy sources have different issues. Renewables represent a clear energy and they don't produce GHG emissions, but they have intermittent nature (wind and solar), their geographical distribution is typically uneven and the variability of renewables requires more operational flexibility to compensate fluctuations. This problem limits their participation in the energy market. In today market with huge share of renewable, some thermal power plants struggle to create high enough profit to cover their investment cost because they are working at very low efficiency or they have a big number of starting up and shutting down what increases operational costs or they don't work at all. Frequent changes of the load cause changes of fuel consumption and emission levels. These changes in the operating modes have a significant effect on the O\&M costs of conventional technologies which in any cause should not be ignored in long term planning and investment costs. According to previous work [1,2], wind power reduces the price of electricity and the attractiveness for the investment in other power stations as gas fired power plants. Feed-in guarantees the purchase of the entire produced electricity, is opposed to the full exposure to market conditions - in other words, exposure to the market price of the electricity and entire responsibility for the deviation of the planned and actual production of electricity. On the other hand, having huge share of stochastic renewables as wind and solar creates need in the system for balancing, especially when the produced electricity is lower than we expected. This working regime forms peaks and gaps and solutions are energy storages, pumped hydro, OCGT and CCGT plants. The option considered in this paper is balancing the wind production with production from CCGT power plants taking into account production cost of three different models of CCGT - model with one, two and three gas turbines and one steam turbine. In this regime CCGT has a possibility to earn additional revenues in the market where one conventional power plant can difficult break through and cover the initial investment and earn profit. Previous works related to this theme $[3,4,5]$ recognised great opportunities in this area by finding a set of optimal solutions in moments when the load is variable which makes CCGT one of the most flexible ways of balancing the unpredictable wind power. 


\section{THE OUTLINE OF THE PROBLEM AND METHODOLOGY}

Objective of this resarch is to examine, on the basis of the model, technical and economic indicators of the CCGT power plant in function of balancing or stabilizing variable electrical production from wind farms according to the different number of gas turbines.

\section{Technical Aspects of CCGT power plant}

Analysis is related to the technical ability, i.e. flexibility of the CCGT power plant for balancing variable production of the wind farms. Whereas this type of drive CCGT depends on the nature of the wind in the area, frequent switching of CCGT plant and the associated high costs are expected [6]. Therefore, three different models are analyzed: 1+1 model (one steam and one gas turbine), $2+1$ model (one steam and two gas turbines) and 3+1 model (one steam and three gas turbines). All three models have the same major characteristics: total installed capacity, as the other related features such as part load efficiency etc.

\section{DESCRIPTION OF THE MODEL}

Model is made in PLEXOS, a software tool for modelling and optimization of relations on the electricity market with prominent comprehensive range of features delivered through a simple interface developed by Energy Exemplar. This is a general simulation tool based on object modelling which defines a hierarchical set of classes, while the user of simulator creates parts or the entire system designing the instances of objects. The definition of the class describes which collections may belong to objects of a particular class and how they act according to the objects of the same or different types. More details regarding modeling approach can be found in [7].

\section{CCGT model}

Analysis is related to the technical ability, i.e. flexibility of the CCGT power plants for following variable production of the wind,whereas this type of drive CCGT depends on the nature of the wind in the area, frequent switching of CCGT plant and the associated high costs are expected. Table 7 and Table 8 are CCGT data taken from elsewhere $[8,9,10,11,12,13,14]$. Following characteristics are used for the purpose of the detailed model of the CCGT power plant according to the given input data: Number of the units of the gas and steam turbines; Installed capacity - maximum; minimum stable power; detailed heat rate curves; FO\&M fee; VO\&M fee; Start-up costs for multiple start profiles; Start-up time for multiple start profiles; Lifting speed of power at the start for multiple start profiles; Lifting 
speed of power in operating mode; Lowering speed of power in operating mode; Motor fuel; Fuel consumption at the start for multiple start profiles; Fuel prices; The limitation of the production; The limitation of the start; auxiliary consumption of the power plant and others.

Table 7. Input data for Gas and Steam Turbine - 1+1 Model

\begin{tabular}{|c|c|c|c|c|c|}
\hline $\begin{array}{c}1+1 \\
\text { Model }\end{array}$ & $\begin{array}{c}\text { Max Cap. } \\
(\mathrm{MW})\end{array}$ & $\begin{array}{c}\text { Min Stable Lvl. } \\
(\mathrm{MW})\end{array}$ & \multicolumn{2}{|c|}{$\begin{array}{c}\text { VO\&M } \\
(€ / \mathrm{MWh})\end{array}$} & $\begin{array}{c}\text { FO\&M } \\
(€ / \mathrm{kW} / \text { year })\end{array}$ \\
\hline GT & 307 & 61.4 & \multicolumn{2}{|c|}{3.22} & 20 \\
\hline ST & 138 & 27.6 & \multicolumn{2}{|c|}{3.22} & \multicolumn{2}{|c|}{20} \\
\hline & $\begin{array}{c}\text { Aux } \\
(\mathrm{MW})\end{array}$ & $\begin{array}{c}\text { Ramp rate } \\
(\mathrm{MW} / \mathrm{min})\end{array}$ & $\begin{array}{c}\text { Eff. } 100 \% \\
(\%)\end{array}$ & $\begin{array}{c}\text { Eff. } 80 \% \\
(\%)\end{array}$ & $\begin{array}{c}\text { Eff. } 20 \% \\
(\%)\end{array}$ \\
\hline GT & 10 & 15.35 & 40 & 38 & 23 \\
\hline ST & 4 & 6.9 & 31.17 & 31.17 & 31.17 \\
\hline
\end{tabular}

Table 8. CCGT start profile data, $1+1$ Model

\begin{tabular}{|c|c|c|c|c|}
\hline Start & Idle Time (hrs) & Fuel Offtake (GJ) & Start Cost $(€)$ & Start Time (min) \\
\hline Hot & 8 & 89.2 & 10235 & 30 \\
\hline Warm & 48 & 93.9 & 14685 & 90 \\
\hline Cold & 96 & 112.67 & 20025 & 190 \\
\hline
\end{tabular}

Table 9. Input data for Gas and Steam Turbine - 2+1 Model

\begin{tabular}{|c|c|c|c|c|c|}
\hline $2+1$ Model & $\begin{array}{c}\text { Max Cap. } \\
(\mathrm{MW})\end{array}$ & $\begin{array}{c}\text { Min Stable Lvl. } \\
(\mathrm{MW})\end{array}$ & $\begin{array}{c}\text { VO\&M } \\
(€ / \mathrm{MWh})\end{array}$ & $\begin{array}{c}\text { FO\&M } \\
(€ / \mathrm{kW} / \text { year })\end{array}$ \\
\hline GT1=GT2 & 153.5 & 30.7 & 3.22 & 20 \\
\hline ST & 138 & 27.6 & 3.22 & 20 \\
\hline & Aux & Ramp rate & Eff. 100\% & Eff. $80 \%$ & Eff. 20\% \\
\hline
\end{tabular}




\begin{tabular}{|c|c|c|c|c|c|}
\hline & $(\mathrm{MW})$ & $(\mathrm{MW} / \mathrm{min})$ & $(\%)$ & $(\%)$ & $(\%)$ \\
\hline GT1=GT2 & 5 & 7.7 & 40 & 38 & 23 \\
\hline ST & 4 & 6.9 & 31.17 & 31.17 & 31.17 \\
\hline
\end{tabular}

Table 10. Input data for Gas and Steam Turbine - 3+1 Model

\begin{tabular}{|c|c|c|c|c|c|}
\hline $3+1$ Model & $\begin{array}{c}\text { Max Cap. } \\
(\mathrm{MW})\end{array}$ & $\begin{array}{c}\text { Min Stable Lvl. } \\
(\mathrm{MW})\end{array}$ & $\begin{array}{c}\text { VO\&M } \\
(€ / \mathrm{MWh})\end{array}$ & $\begin{array}{c}\text { FO\&M } \\
(€ / \mathrm{kW} / \text { year })\end{array}$ \\
\hline GT1=GT2=GT3 & 102.33 & 20.47 & \multicolumn{2}{|c|}{3.22} & 20 \\
\hline ST & 138 & 27.6 & \multicolumn{2}{|c|}{3.22} & 20 \\
\hline & $\begin{array}{c}\text { Aux } \\
(\mathrm{MW})\end{array}$ & $\begin{array}{c}\text { Ramp rate } \\
(\mathrm{MW} / \mathrm{min})\end{array}$ & $\begin{array}{c}\text { Eff. } 100 \% \\
(\%)\end{array}$ & $\begin{array}{c}\text { Eff. } 80 \% \\
(\%)\end{array}$ & $\begin{array}{c}\text { Eff. } 20 \% \\
(\%)\end{array}$ \\
\hline GT1=GT2=GT3 & 3.33 & 5.117 & 40 & 38 & 23 \\
\hline ST & 4 & 6.9 & 31.17 & 31.17 & 31.17 \\
\hline
\end{tabular}

\section{Electricity market model}

Prices are taken from the stock exchange EPEX for the year 2014.

\section{Wind model}

In order to take into account interdependence of wind speeds in neighboring hours ARIMA (Auto Regressive Integrated Moving Average) modelling approach basic statistical parameters are used. The ARIMA models are traditionally very well suited to capture short range correlations, and hence have been used extensively in a variety of forecasting applications. ARIMA model predicts future values of a time series by a linear combination of its past values and a series of errors. Three different patterns of wind have provided three different scenarios with capacity factors: $33 \%, 24 \%$ and $61 \%$. First two patterns have the same stochastic parameters (Table 11) but different capacity factors. It could be considered as a wind with same stochastic parameters but in two different weeks in year. Mean values and standard deviation in third scenario are higher and represent a strong wind, which can occur in some occasions, used to show impact of the higher wind capacity on the CCGT production price. Each scenario has five cases with different maximum value, mean value and deviation. Case one is wind with highest 
maximum value (400 MW) and Case 5 with lowest maximum value (100 MW). The data used for wind modelling can be found in Table 11 and Table 12.

Table 11. Wind power output stochastic parameters for wind capacity factor $33 \%$ and $24 \%$

\begin{tabular}{|l|c|c|c|c|c|}
\hline & $\begin{array}{c}\text { Min Value } \\
(\mathrm{MW})\end{array}$ & $\begin{array}{c}\text { Max Value } \\
(\mathrm{MW})\end{array}$ & $\begin{array}{c}\text { Mean Value } \\
(\mathrm{MW})\end{array}$ & $\begin{array}{c}\text { Std. Dev. } \\
(\mathrm{MW})\end{array}$ & $\begin{array}{c}\text { ARIMA a } \\
\& \mathrm{~b}\end{array}$ \\
\hline Case 1 & 0 & 400 & 104 & 92 & 0.5 \\
\hline Case 2 & 0 & 300 & 78 & 69 & 0.5 \\
\hline Case 3 & 0 & 200 & 52 & 46 & 0.5 \\
\hline Case 4 & 0 & 150 & 39 & 34,5 & 0.5 \\
\hline Case 5 & 0 & 100 & 26 & 23 & 0.5 \\
\hline
\end{tabular}

Table 12 Wind power output stochastic parameters for wind capacity factor $61 \%$

\begin{tabular}{|l|c|c|c|c|c|}
\hline & $\begin{array}{c}\text { Min Value } \\
(\mathrm{MW})\end{array}$ & $\begin{array}{c}\text { Max Value } \\
(\mathrm{MW})\end{array}$ & $\begin{array}{c}\text { Mean Value } \\
(\mathrm{MW})\end{array}$ & $\begin{array}{c}\text { Std. Dev. } \\
(\mathrm{MW})\end{array}$ & $\begin{array}{c}\text { ARIMA a } \\
\& \mathrm{~b}\end{array}$ \\
\hline Case 1 & 0 & 400 & 200 & 200 & 0.5 \\
\hline Case 2 & 0 & 300 & 150 & 150 & 0.5 \\
\hline Case 3 & 0 & 200 & 100 & 100 & 0.5 \\
\hline Case 4 & 0 & 150 & 75 & 75 & 0.5 \\
\hline Case 5 & 0 & 100 & 50 & 50 & 0.5 \\
\hline
\end{tabular}

\section{Dummy generator model}

Dummy power plant is super flexible power plant which marginal cost and cost of launching are significantly larger than the marginal cost of CCGT units, but significantly lower than in the model defined VoLL. Dummy generator is activated only in cases when CCGT power plant achieves technical limits. Modelled Dummy has same characteristics as in [7] - max capacity of 500 MW and VO\&M cost of $5000 € / \mathrm{MWh}$. amount of VoLL in the model is fixed on $100000 € / \mathrm{MWh}$ to 
ensure activation of Dummy generator only in case of an emergency and generator activation price is $€ 1,000,000$.

\section{Electricity consumption model}

Consumption is fixed amount which is equal throughout the entire optimization period, but different in each scenario. Consumption is changing depending on the modelled wind power level.

\section{RESULTS AND DISCUSSION}

The presented results were obtained on $3.6 \mathrm{GHz}$ based processor with $32 \mathrm{~GB}$ RAM using CPLEX solver under PLEXOS $® 7$. Results are presented for the three different patterns of wind, with three different wind capacity factors. For each wind capacity factor there are examined three different models of CCGT at different wind levels (as is shown in Table 11 and Table 12) in order to examine the impact of gas turbine number on CCGT production cost.

Fig. 25 represents wind with capacity factor $33 \%$ and maximum power output 100 MW. Fig. 26 is wind with capacity factor $24 \%$ and maximum output $100 \mathrm{MW}$. Wind with capacity factor $33 \%$ and wind with capacity factor $24 \%$ have the same average power and standard deviation. Fig. 27 is wind with capacity factor $61 \%$. Profile and deviation of wind on Fig. 27 is higher and it can be characterized as a strong wind. Each figure represents the data for the one week in hourly resolution.

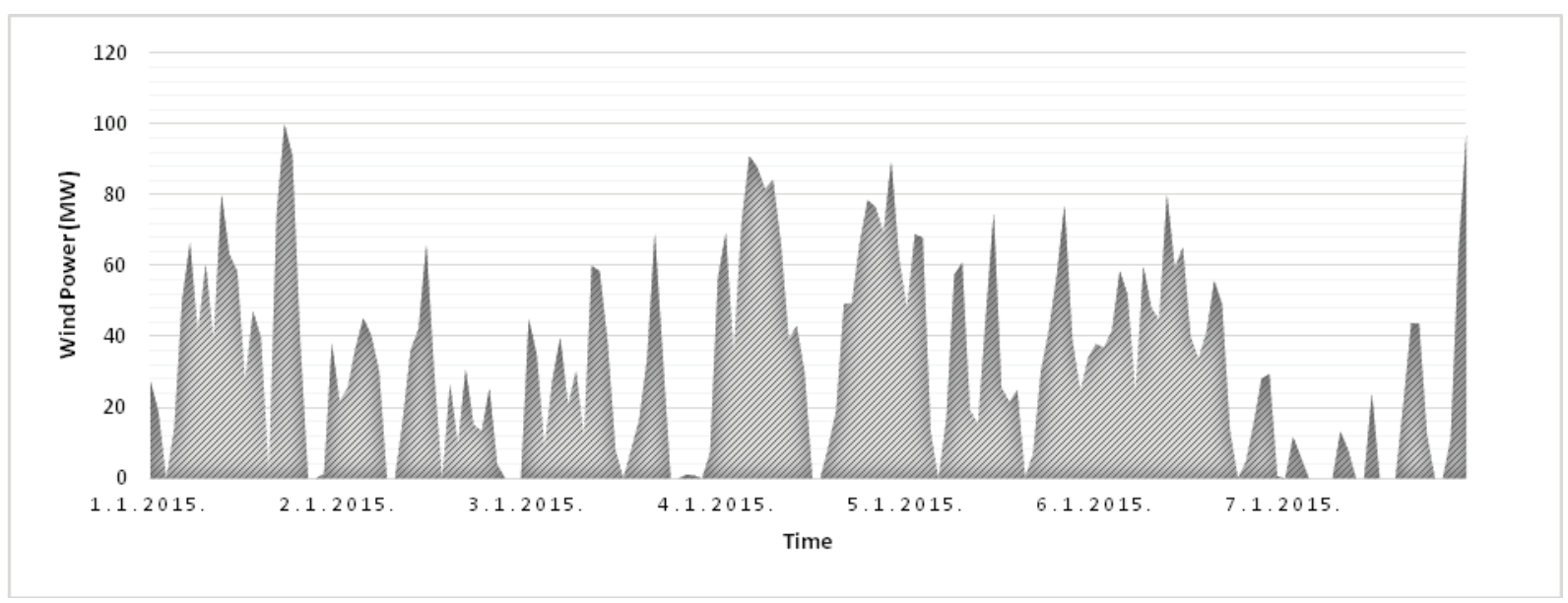

Fig. 25 Profile of wind, capacity factor $=33 \%$, case 5 ( $\max$ wind power $100 \mathrm{MW})$ 


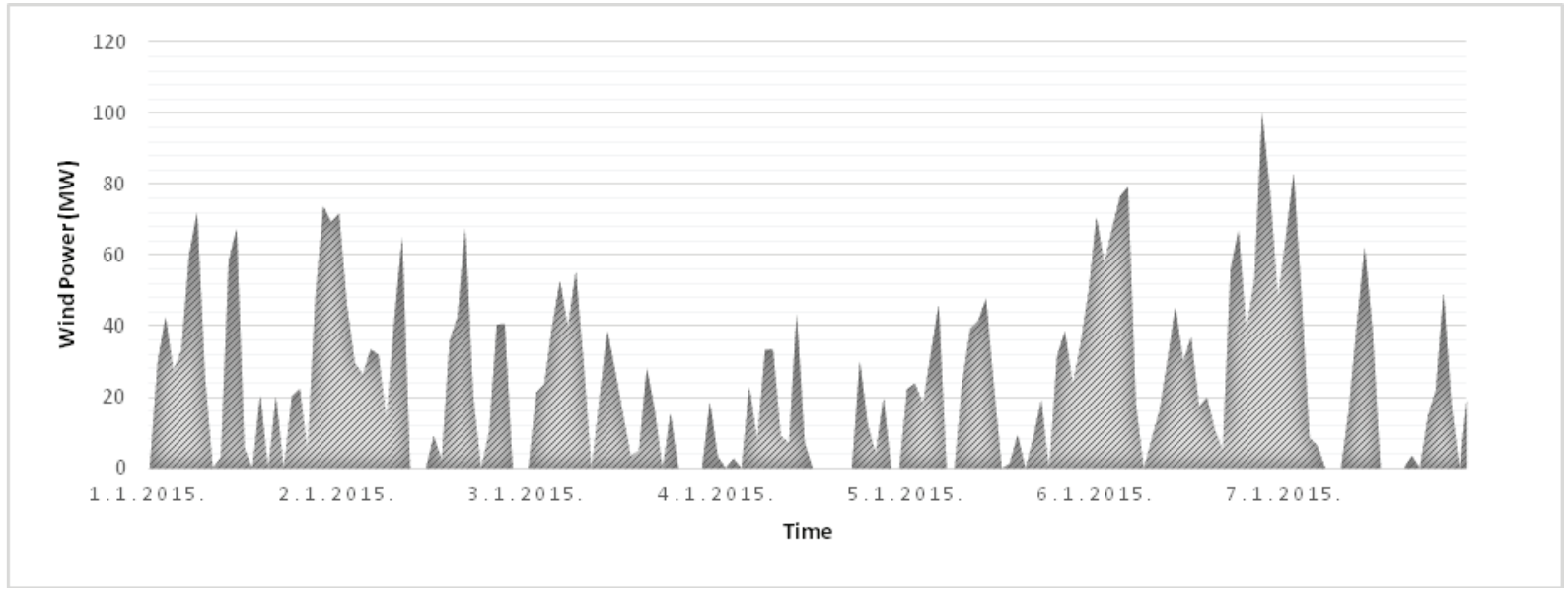

Fig. 26 Profile of wind, capacity factor $=24 \%$, case 5 ( $\max$ wind power $100 \mathrm{MW})$

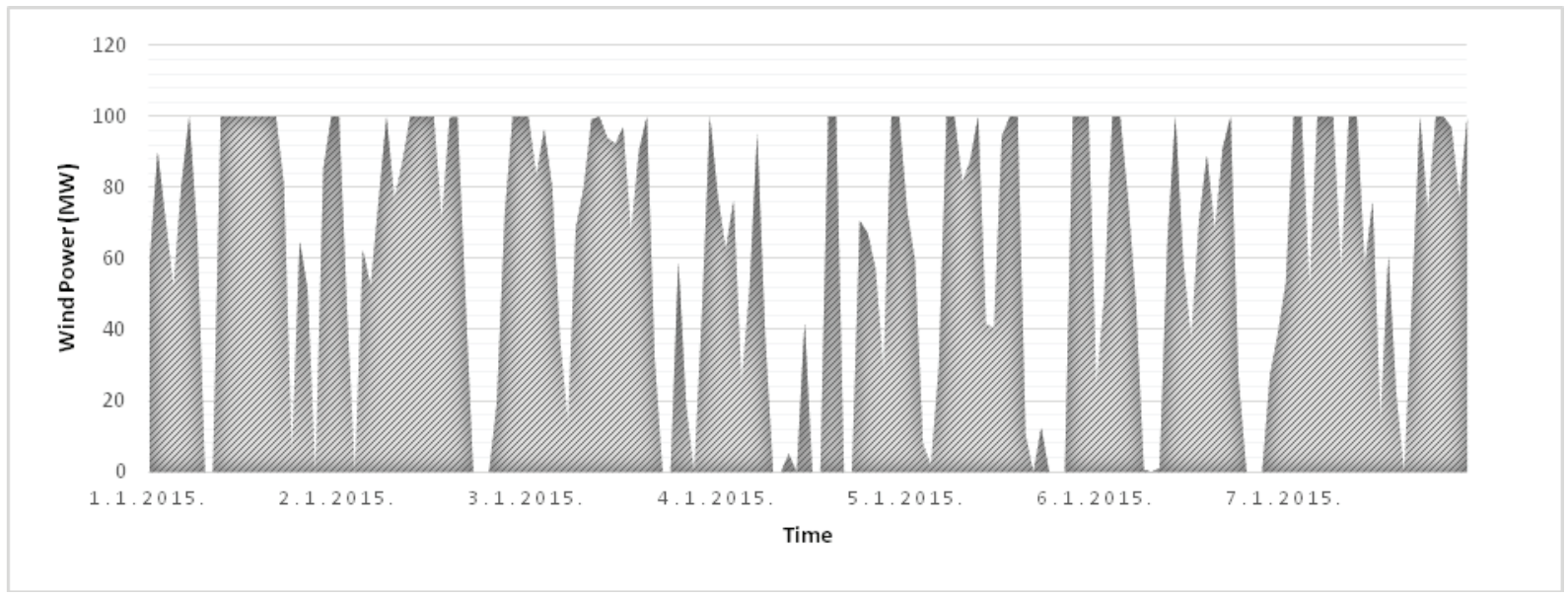

Fig. 27 Profile of wind, capacity factor $=61 \%$, case 5 (max wind power $100 \mathrm{MW}$ )

In this research cost of production and unserved energy are analysed for three models of CCGT power plant: 1+1 model (CCGT with one gas turbine and one steam turbine), $2+1$ model (CCGT with two gas turbines and one steam turbine) and 3+1 model (CCGT with three gas turbines and one steam turbine). Results form optimization tool PLEXOS can be found on following figs. 4 and 5. Fig 4 illustrates cost of production and and Fig. 5 is for unserved energy for the case 5 (maximum wind power $100 \mathrm{MW}$ ) in three different scenarios (wind capacity factor $33 \%, 24 \%$ and $61 \%$ ). 


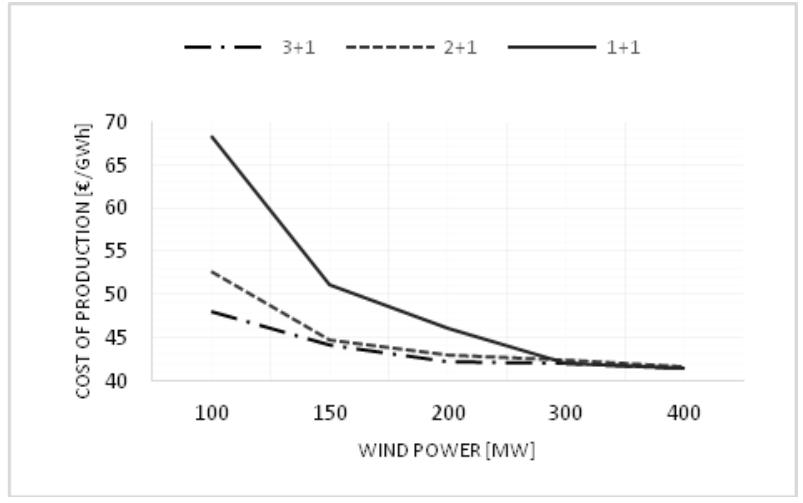

Fig. 28 Cost of production for $1+1,2+1$ and $3+1$ model for scenario 1 (wind capacity factor

$=33 \%$ ) and case 5 (wind production 5.54 GWh)

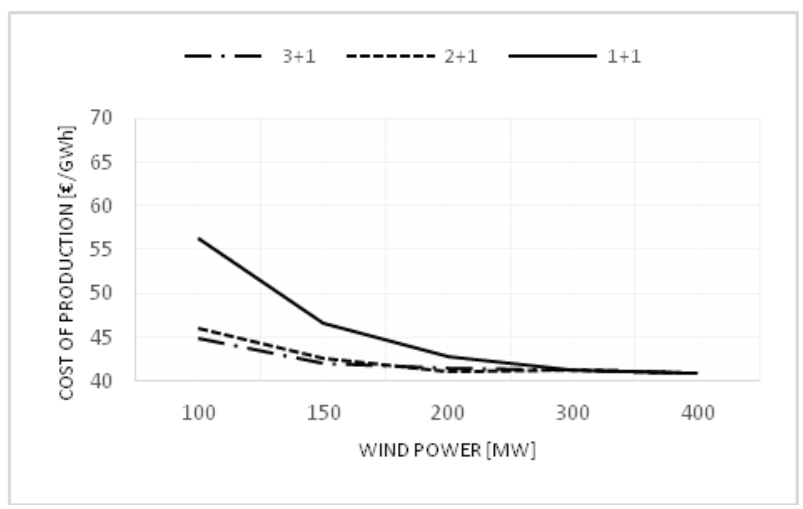

Fig. 30 Cost of production for $1+1,2+1$ and $3+1$ model scenario 2 (wind capacity factor $=$ $24 \%$ ) and case 5 (wind production $5.54 \mathrm{GWh}$ )

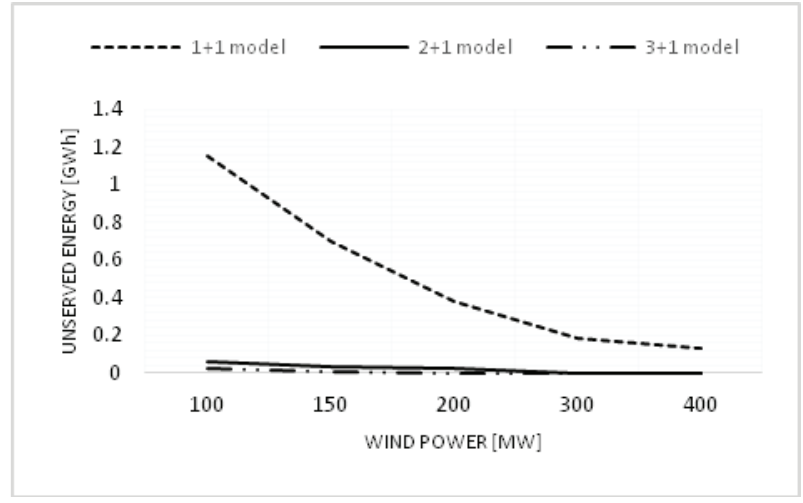

Fig. 29 Unserved energy for 1+1, 2+1 and 3+1 model for scenario 1 (wind capacity factor $=$ $33 \%$ ) and case 5 (wind production 5.54 GWh)

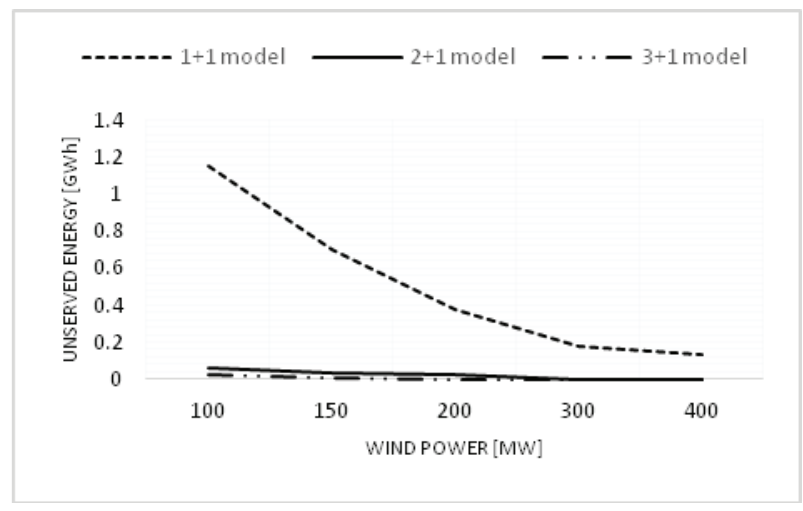

Fig. 31 Unserved energy for $1+1,2+1$ and $3+1$ model for scenario 2 (wind capacity factor $=$ $24 \%$ ) and case 5 (wind production $5.54 \mathrm{GWh}$ )

Fig. 30 and Fig. 32 shows that wind nature, which CCGT is balancing, has a significant impact on decision on number of gas turbines. On the lower wind power levels, it is very important if CCGT has one, two or three gas turbines. CCGT with one gas turbine has a lower efficiency at low power outputs (100-200 MW) than CCGT with two or three gas turbines. Due to lower flexibility, CCGT with one gas turbine has to shut down and start up more often resulting in increased costs (start up cost, consumption of the fuel). That difference is significant: in scenario with wind capacity factor of $61 \%$ difference in cost of production between CCGT model with one and three gas turbines is slightly less than $40 € / \mathrm{GWh}$. If the wind power level in the system is higher (300-400 MW), 
difference in these costs becomes smaller, especially difference between CCGT models with two and three gas turbines. If the wind power is higher than $150 \mathrm{MW}$, the both, two turbines and three turbines model, have very high efficiency and flexibility regarding balancingw the wind production. For the power levels higher than $300 \mathrm{MW}$ number of gas turbines it is no more important because costs of production are almost the same - all three models have high efficiency at these power levels.

It is also very important to notice the influence of the wind capacity factor on CCGT production costs. In the scenario with largest wind capacity factor (capacity factor $61 \%$ ) CCGT cost of production is significantly larger in comparison with scenarios with lower wind capacity factors (capacity factors 33 and 24\%), regardless of wind power level and CCGT model. As can be seen from Fig. 31 and Fig. 33, unserved energy in each scenario depends on number of gas turbines; for the CCGT power plant with one gas turbine unserved energy is significatly higher than unserved energy for the CCGT plant with two or three turbines due to higher min stable level value.

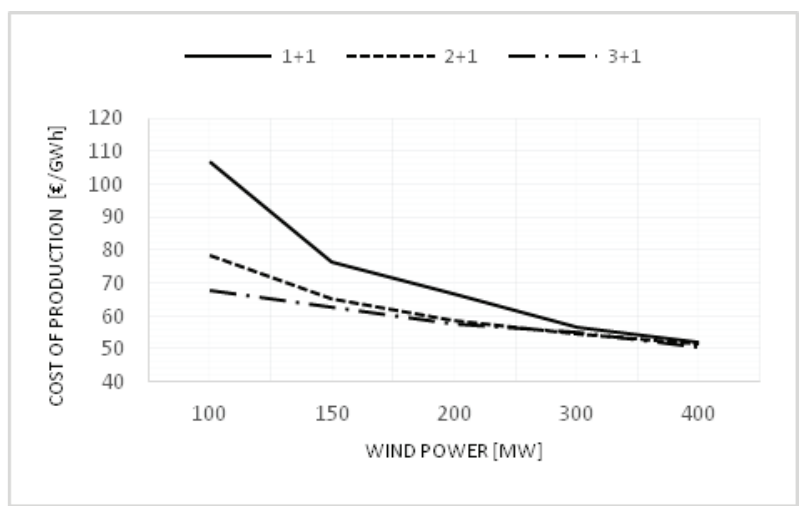

Fig. 32 Cost of production for $1+1,2+1$ and $3+1$ model for scenario 3 (wind capacity factor $=61 \%$ ) case 5 (wind production $5.54 \mathrm{GWh}$ )

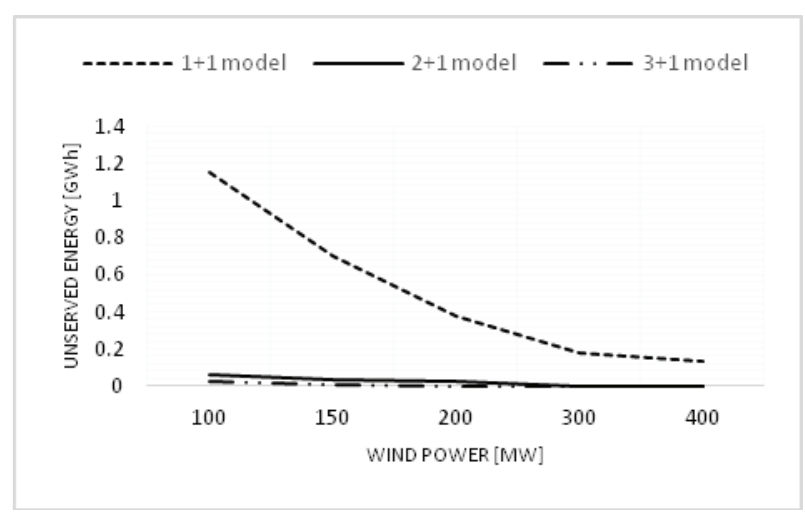

Fig. 33 Unserved energy for $1+1,2+1$ and $3+1$ model for scenario 3 (wind capacity factor $=$ $61 \%$ ) and case 5 (wind production $5.54 \mathrm{GWh}$ )

Detailed data regarding production of each power plant in the modeled system for each scenario and case can be found in Appendix. 


\section{CONCLUSION}

This paper presents techno-economic analysis for the balancing of volatile nature of renewables, in this case wind farms, with different CCGT power plant models having different number of gas turbine as basis for results comparison.

Investments in the CCGT power plant with one gas turbine is lower than investment in CCGT with two or three gas turbines. The CCGT with one gas turbine has a low efficiency and flexibility at lower load and consequently higher costs because of limitations as the limited speed of raising power and limited speed of the start and those limitations have a huge impact on the production costs.

In order to avoid restrictions associated with the start of the CCGT power plant it is desirable that CCGT constantly has load higher than minimum stable level, but in the system with a huge share of renewables it is not often possible. If CCGT often works at lower capacity it is better to have more gas turbines which will result in decrease of production cost while if the load is higher, all three CCGT models will come in the area with good efficiency and all three CCGT models will have almost the same production cost.

\section{BIBLIOGRAPHY}

[1] T. Traber and C. Kemfert, "Gone with the Wind?: Electricity Market Prices and Incentives to Invest in Thermal Power Plants under Increasing Wind Energy Supply," 2009.

[2] W. I. Horowitz, J. Moore and A. Pacheco, "The impact of wind generation on the electricity spot-market price level and variance: The Texas experience," Energy Policy, no.7, pp. 3939-3944, July 2011.

[3] M. Valdés, M. D. Duran and A. Rovira, "Thermoeconomic optimization of combined cycle gas turbine power plants using genetic algorithms," Applied Thermal Engineering, no. 17, pp. 2169-2182, December 2003.

[4] A. Rovira, C. Sánchez, M. Muñoz and M. D. Duran, "Thermoeconomic optimisation of heat recovery steam generators of combined cycle gas turbine power plants considering off-design operation," Energy Conversion and Management, no. 4, pp. 1840-1849, April 2011.

[5] E. Godoy, J. S. N. and J. B. S., "Families of optimal thermodynamic solutions for combined cycle gas turbine," Applied Thermal Engineering, pp. 569-576, 2010.

[6] E. Mearns, "The balancing capacity issue: A ticking time-bomb under the UK's Energiewende," Energy Matters, 30 June 2014. [Online]. Available: http://euanmearns.com/the-balancing-capacity-issue-a-ticking-time-bomb- 
under-the-uks-energiewende/. [Accessed April 2016].

[7] Ž. Tomšić, I. Rajšl and M. Filipović, "Techno-Economic analysis of common work of Wind and CCGT plant by offering continuous level of power to electricity market," in 11th Conference on Sustainable Development of Energy, Water and Environment Systems - SDEWES , Lisabon, Portugal, 2016.

[8] Siemens AG Energy Sector, Flexible performance, convincing quality economical and future-proof packages SGT5-PAC 4000F, 2014.

[9] WBCSD Cement Sustainability Initiative (CSI) / ECRA GmbH, "List of Constants and Default CO2 emission factors," 8 December 2014. [Online]. Available: http://www.cement-co2protocol.org/v3/Content/Internet_Manual/constants.htm. [Accessed March 2016].

[10] C. L. Hart and J. G. Wright, "Gas power plant fuel requirements and uncertainty considering increasing renewables penetration," in African Utility Week, Cape Town, 2015.

[11] D. Chase and P. Kehoe, GE Combined-Cycle Product Line and Performance, GE Power Systems.

[12] N. Kumar, P. M. Besuner, S. A. Lefton, D. D. Agan and D. D. Hilleman, "Power Plant Cycling Costs," Intertek APTECH, 2012.

[13] A. Schröder, F. Kunz, J. Meiss, R. Mendelevitch and C. v. Hirschhausen, "Current and Prospective Costs of Electricity Generation until 2050," DIW BERLIN - Deutsches Institut für Wirtschaftsforschung, Berlin, 2013.

[14] S. Simoes, W. Nijs, P. Ruiz, A. Sgobbi, D. Radu, P. Bolat, C. Thiel and S. Peteves, "The JRC-EU-TIMES model - Assessing the long-term role of the SET PLan Energy technologies," European Commission, Joint Research Centre, Institute for Energy and Transport, 2013.

\section{Appendix}

Table 13 Production of CCGT, Dummy and Wind power plant for scenario 1

\begin{tabular}{|c|c|c|c|c|c|c|}
\hline Model & Load [MW] & 100 & 150 & 200 & 300 & 400 \\
\hline \multicolumn{7}{|c|}{$1+1$} \\
\cline { 2 - 7 }
\end{tabular}




\begin{tabular}{|c|l|l|c|c|c|c|c|}
\hline \multirow{3}{*}{$2+1$} & Wind & 5.54 & 8.3 & 11.07 & 16.61 & 22.14 \\
\cline { 3 - 8 } & CCGT & 11.2 & 16.87 & 22.51 & 33.79 & 45.06 \\
\cline { 3 - 8 } $3+1$ & Dummy & 0.06 & 0.03 & 0.02 & 0 & 0 \\
\cline { 3 - 8 } & Wind & 5.54 & 8.3 & 11.07 & 16.61 & 22.14 \\
\cline { 3 - 8 } & CCGT & 11.24 & 16.89 & 22.53 & 33.79 & 45.06 \\
\cline { 2 - 8 } & Dummy & 0.02 & 0.01 & 0 & 0 & 0 \\
\cline { 2 - 8 } & Wind & 5.54 & 8.3 & 11.07 & 16.61 & 22.14 \\
\hline
\end{tabular}

Table 14 Production of CCGT, Dummy and Wind power plant for scenario 2

\begin{tabular}{|c|c|c|c|c|c|c|c|}
\hline Model & \multicolumn{2}{|c|}{ Load [MW] } & 100 & 150 & 200 & 300 & 400 \\
\hline \multirow{3}{*}{$1+1$} & \multirow{9}{*}{ 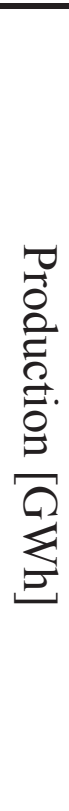 } & $\overline{\mathrm{CCGT}}$ & 11.88 & 18.57 & 25.32 & 38.07 & 50.83 \\
\hline & & Dummy & 0.83 & 0.49 & 0.09 & 0.05 & 0 \\
\hline & & Wind & 4.09 & 6.14 & 8.19 & 12.28 & 16.37 \\
\hline \multirow{3}{*}{$2+1$} & & CCGT & 12.7 & 19.05 & 25.41 & 38.12 & 50.83 \\
\hline & & Dummy & 0.01 & 0.01 & 0 & 0 & 0 \\
\hline & & Wind & 4.09 & 6.14 & 8.19 & 12.28 & 16.37 \\
\hline \multirow{3}{*}{$3+1$} & & CCGT & 12.71 & 19.06 & 25.41 & 38.12 & 50.83 \\
\hline & & Dummy & 0 & 0 & 0 & 0 & 0 \\
\hline & & Wind & 4.09 & 6.14 & 8.19 & 12.28 & 16.37 \\
\hline
\end{tabular}

Table 15 Production of CCGT, Dummy and Wind power plant for scenario 3

\begin{tabular}{|l|l|l|l|l|l|l|}
\hline Model & Load [MW] & 100 & 150 & 200 & 300 & 400 \\
\hline
\end{tabular}




\begin{tabular}{|c|c|c|c|c|c|c|c|}
\hline \multirow{3}{*}{$1+1$} & \multirow{9}{*}{ 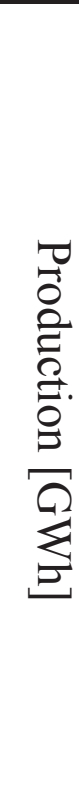 } & CCGT & 5.28 & 3.85 & 17.59 & 19.17 & 25.68 \\
\hline & & Dummy & 1.23 & 0.76 & 0.57 & 0.35 & 0.34 \\
\hline & & Wind & 10.29 & 20.59 & 15.44 & 30.88 & 41.18 \\
\hline \multirow{3}{*}{$2+1$} & & CCGT & 6.29 & 4.45 & 18.05 & 19.46 & 25.96 \\
\hline & & Dummy & 0.22 & 0.16 & 0.11 & 0.06 & 0.06 \\
\hline & & Wind & 10.29 & 20.59 & 15.44 & 30.88 & 41.18 \\
\hline \multirow{3}{*}{$3+1$} & & CCGT & 6.44 & 4.58 & 18.14 & 19.51 & 26.01 \\
\hline & & Dummy & 0.07 & 0.03 & 0.02 & 0.01 & 0.01 \\
\hline & & Wind & 10.29 & 20.59 & 15.44 & 30.88 & 41.18 \\
\hline
\end{tabular}

